\title{
Pharmacogenetics of antiparkinsonian drug treatment: a systematic review
}

\section{MauritsEL Arband,2, Jeroen PP van Vugt, TaineCG Egbetr,4 \& Henk-Jan Gudhdaar 5 t}

${ }^{\dagger}$ Author for correspondence ${ }^{1} U$ trecht U niversity, Division of Pharmacoepidemiology and Pharmacotherapy, $U$ trecht Institute for Pharmaceutical Sciences, Faculty of Sciences, U trecht, The N etherlands $2 \mathrm{M}$ edisch Spectrum Twente, D epartment of Clinical Pharmacy, Enschede, The N etherlands ${ }^{3} \mathrm{M}$ edisch Spectrum Twente, D epartment of N eurology, Enschede, The N etherlands ${ }^{4} U$ niversity M edical Center U trecht, D epartment of Clinical Pharmacy, U trecht, The N etherlands ${ }^{5}$ Leiden U niversity M edical Center, D epartment of Clinical Pharmacy and Toxicology, PO Box 9600, 2300 RC Leiden,

The N etherlands

Tel.: +31 715262790 ; Fax: +31715248101 E-mail: h.j.guchelaar@ lumc.nl

\section{Keywords: apolipoproteineE, budipine, catechol-0 -methyltransferase, cholecystokinin, dopamine, entacapone, hypocretin, levodopa, monoamine- oxidase, opioid, Parkinson's disease, pergolide, P-glycoprotein, pharmacogenetics, pharmacotherapy, pramipexole, receptors, ropinirole, serotonin, tolcapone}

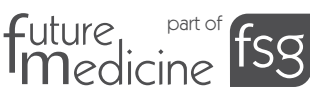

Pharmacotherapy is the mainstay in the treatment of Parkinson's disease and the armamentarium of drugs available for the therapy of this disease is still expanding. Anti-Parkinson's disease drugs are effective in reducing the physical symptoms, such as hypokinesia, bradykinesia, rigidity and tremor. However, there is a large interindividual variability in response to anti-Parkinson's disease drugs with respect to both drug efficacy and toxicity. It is thought that genetic variability in genes encoding drug-metabolizing enzymes, drug receptors and proteins involved in pathway signaling is an important factor in determining interindividual variability in drug response. Pharmacogenetics aims at identifying genetic markers associated with drug response. Ideally, knowledge of these genetic markers will enable us to predict an individual's drug response in terms of both efficacy and toxicity. The role of pharmacogenetics in the treatment of Parkinson's disease is relatively unexplored. Therefore, we aim to present a systematic review of the published pharmacogenetic studies in Parkinson's disease and to describe polymorphic genes of interest for future research.

Parkinson's disease (PD) is characterized by bradykinesia, rigidity and tremor, and is the result of degeneration of dopaminergic neurones in the substantia nigra pars compacta. D espite knowledge of genetics in familial PD, the knowledge of the common, late-onset form of PD remains limited. The ultimate goal, prevention of the disease, is still far away. The pharmacological and the nonpharmacological symptomatic treatment is therefore still the only choice.

The motor symptoms of PD can be controlled pharmacologically by increasing dopaminergic neurotransmission. This is achieved by treatment with levodopa, which is taken up by dopaminergic terminals and converted into dopamine by 3,4-dihydroxyphenylalanine (DO PA) decarboxylase. Alternatively, dopamine agonists are employed that directly stimulate the postsynaptic dopamine receptors acting relatively selectively upon the dopamine D 2-like receptors (D 2, D 3 or $D 4$ ) over the D 1-like receptors (D 1 or D 5).

U se of both levodopa and the direct-acting dopamine agonists are associated with the development of motor complications such as fluctuations in response to medication. Psychotic side-effects, such as hallucinations, and excessive daytime sleepiness also occur. H owever, there is a large interindividual variability in response to anti-PD drugs both with respect to drug efficacy and toxicity. It is thought that genetic variability in genes encoding drugmetabolizing enzymes, drug receptors and proteins involved in pathway signaling is an important factor in determining interindividual variability in drug response.

Indeed, several investigators have studied genetic variability with regard to drug response in PD. Until now, one review on pharmacogenetics of PD has been published, but this provides only a concise summary on drug-related response and complications in PD [1]. Therefore, we conducted a systematic literature search and summarized published studies that are reported in the current review.

\section{Search criteria}

We used the following methodology. PubM ed was searched with the $\mathrm{MeSH}{ }^{\circledR}$ headings 'Parkinson disease/drug therapy/*genetics' [101]. Also the combination of the keywords 'Parkinson's disease' and 'pharmacogenetics', 'alleles', 'genotype', 'polymorphism', 'dyskinesia', 'psychosis', 'hallucinations', 'sleep attacks', 'drug response', or 'wearing off' was used. For identification of articles not indexed in PubM ed, a search in Embase was performed with the keywords 'pharmacogenetics' combined with 'Parkinson' [102]. Articles collected until July 2006, published in English, that described an association study in humans on antiPD drug effect or side effect and a genetic polymorphism were included. All references in selected articles were screened and included when of interest. A cited reference search in W eb of Science [103] was done in order to identify missing 
articles. Finally, we have checked two genetics databases for additional published articles [104,105]. We did not include criteria for the quality of the selected articles, as the total number of articles published on the subject is relatively low. Case reports were not included.

\section{Search results}

We identified 29 articles studying pharmacogenetics in $\mathrm{PD}$, of which two articles were excluded. O ne was excluded because cases were only compared with healthy controls [2]; the other study was excluded because the different genotypes were not statistically compared [3]. We include one article that was published as a letter [4]. Of the remaining 27 studies, most studies used a case-control design $(n=18$; $67 \%)$, others ( $n=4 ; 15 \%)$ used data from randomized clinical trials or applied a levodopa challenge test $(n=4 ; 15 \%)$. O ne study was a prospective crossover trial $(4 \%)$. The characteristics of these studies are summarized in Table 1.

\section{Candidate genes}

The candidate genes under study might be classified in different ways. First, a classification based on pharmacokinetic and pharmacodynamic principles might be made, that is, polymorphisms in drug-metabolizing enzymes versus polymorphisms in receptors and in proteins involved in drug response. However, until now no pharmacokinetic polymorphism (e.g., a cytochrome P450 polymorphism) has been studied in patients with PD in relation to drug response. Another way to classify candidate genes might be to distinguish direct and indirect genes, based on the degree with which the protein product of the gene actually interacts with the drug in question. For example, the catechol-0-methyl transferase (COM T) gene would be considered direct for levodopa and COMT inhibitor response. In contrast, apolipoprotein E (APOE) and cholecystokinin (CCK) genes would be considered indirect for levodopa response. Selecting direct candidate genes over indirect ones will minimize false-positive results and increase the likelihood of identifying a true association. We have used this concept, introduced by $M$ asellis and colleagues, in the sel ection of candidate genes under study [5].

\section{Dopamine receptor polymorphisms}

Dopamine receptor $\mathrm{D} 1$

D opamine receptor (DR)D 1 is involved in the dopaminergic response to exogenous levodopa in patients with PD. Messenger RNA for
DRD 1 is most abundant in caudate, nucleus accumbens with little or no messenger ( $m$ )R N A detectable in substantia nigra [6]. Polymorphism of the genes coding for this receptor, located on chromosome 5 , could therefore be implicated in the genetic susceptibility to variability in efficacy and adverse effects of anti-PD treatment. Furthermore, DRD 1 modulates dopamine receptor $D 2$-mediated events [7]. Of interest are the $-48 A>G(D 1.1 ; B 1 / B 2)$ polymorphism in the $5^{\prime}$ untranslated region (UTR), the 1403T $>C$ (D 1.7; C 1/C 2) polymorphism in the $3^{\prime}$ UTR and the Ser421Ser polymorphism [8]. The gene coding for DRD 1 is considered to be a direct gene for levodopa therapy (actually for dopamine) and for some dopamine agonists.

\section{Dopamine receptor $\mathrm{D} 2$}

The DRD 2 gene is located on chromosome 11 and encodes a long (D 2L) and short (D 2S) isoform with distinct functions. D $2 \mathrm{~L}$ acts mainly at postsynaptic sites and D2S serves presynaptic autoreceptor functions. The D RD 2 gene is mainly expressed in the dorsal regions of the striatum (both the putamen and the caudate nucleus) and also in the ventral striatum and the globus pallidus $[9,10]$. Signaling through DRD 2 receptors governs physiologic functions related to locomotion and drug abuse [11]. Several polymorphisms in the DRD 2 gene are known. It has been shown that individuals carrying the $\mathrm{A} 1$ allele of the TaqlA polymorphism have a low striatal D RD 2 receptor density [12] and may affect substrate binding specificity [13]. Recently, it has been shown that the Taql A restriction fragment length polyorphism, a $C>T$ base change, is located in a novel kinase gene, named ankyrin repeat and kinase domain containing 1 (ANKK1), which is located downstream of the DRD 2 gene. This polymorphism may affect substrate binding specificity [13]. The TaqlA polymorphism was implicated in smoking behavior and alcoholism, but this association remains controversial.

Furthermore, the DRD 2 gene has a -141C insertion (ins)/deletion (del) polymorphism in the promoter region resulting in an increased $\mathrm{mRN} A$ expression for the -141C ins-allele [14], and a higher striatal DRD 2 density [15]. An intronic CA dinucleotide short tandem repeat (CAnST R) polymorphism in a noncoding region has been studied in relation to response to anti-PD drugs [16].

The gene coding for DRD 2 is considered to be a direct gene for levodopa therapy and dopamine agonists. 


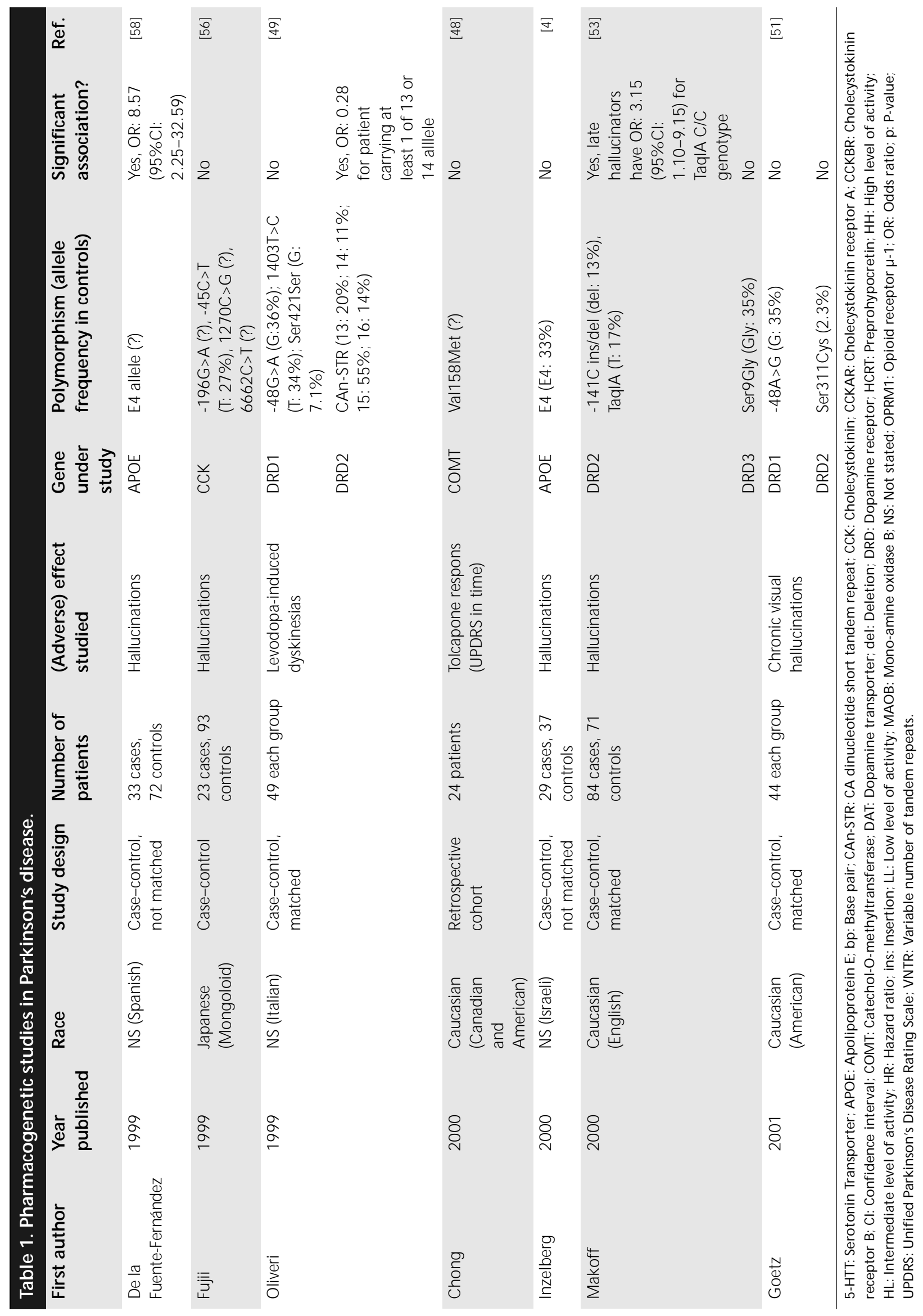




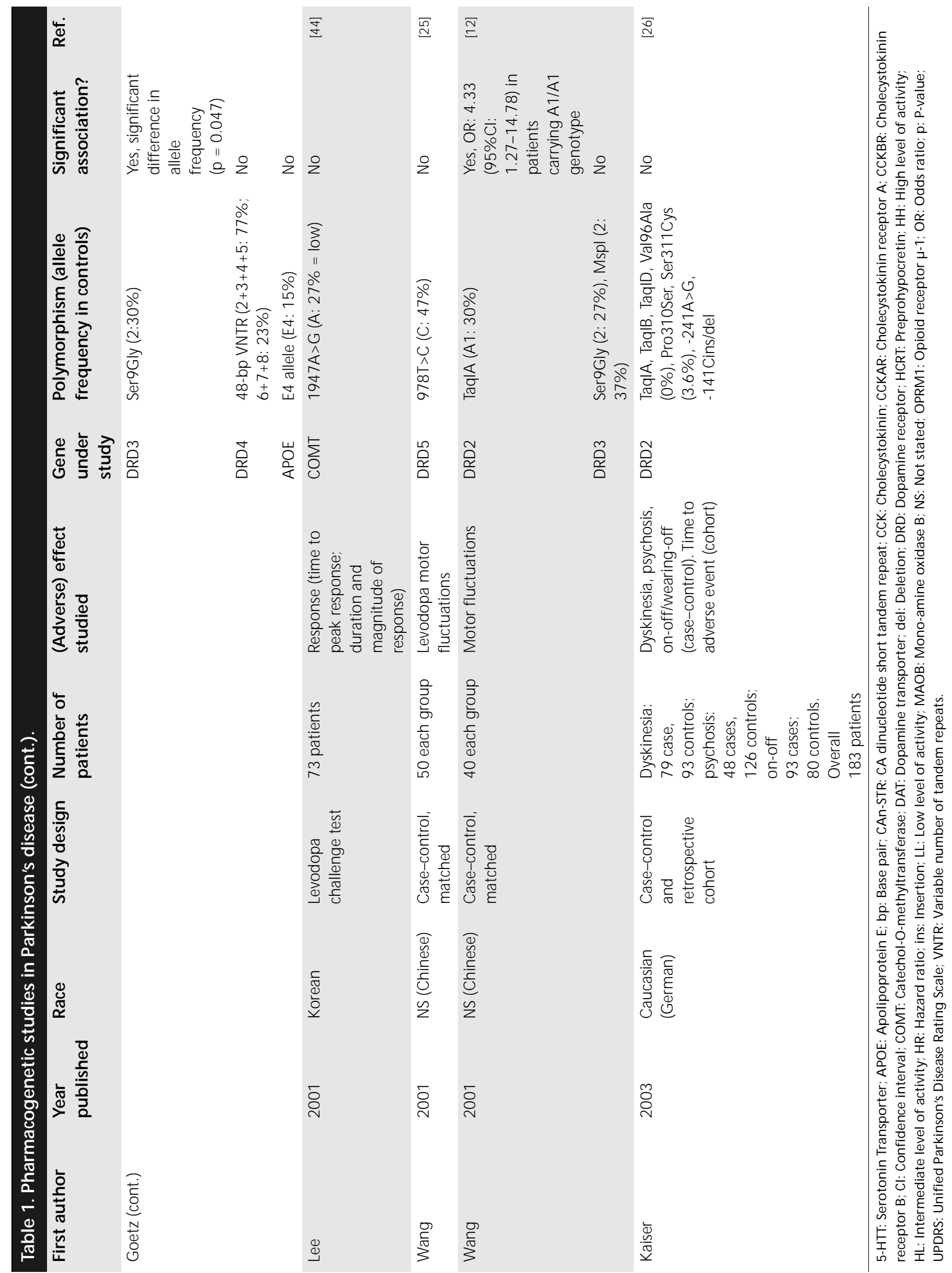


Pharmacogenetics of antiparkinsonian drug treatment: a systematic review - REVIEW

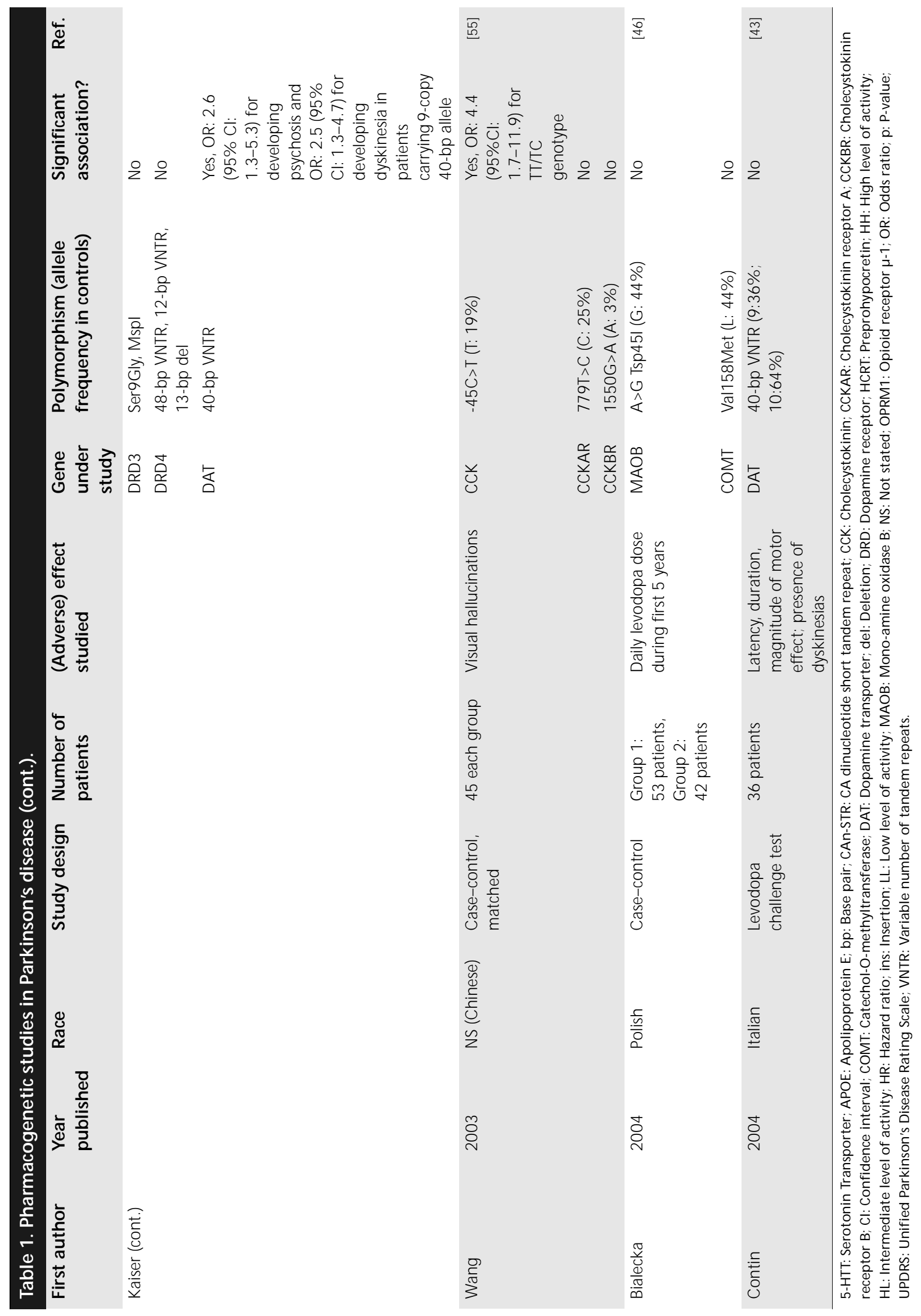




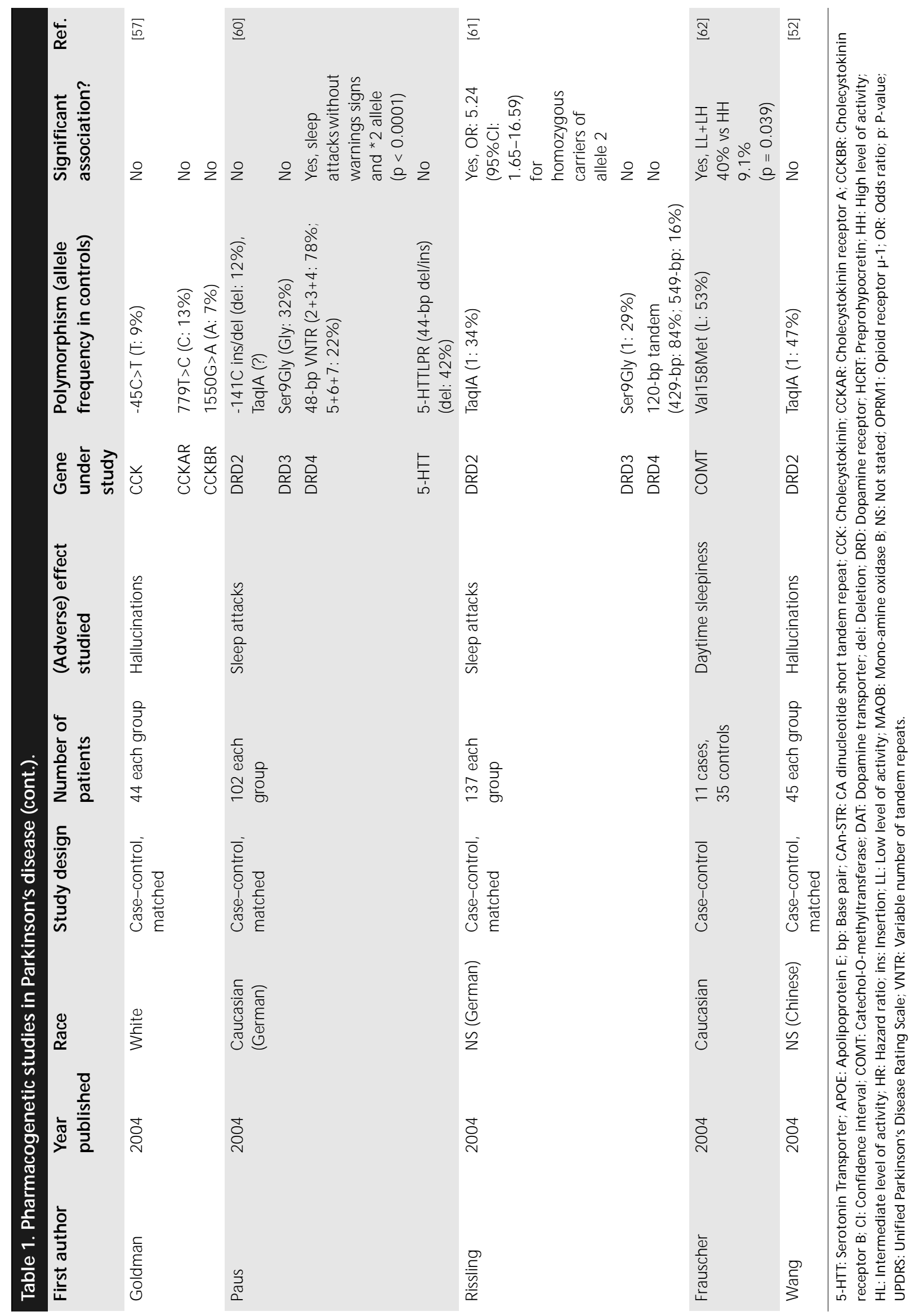




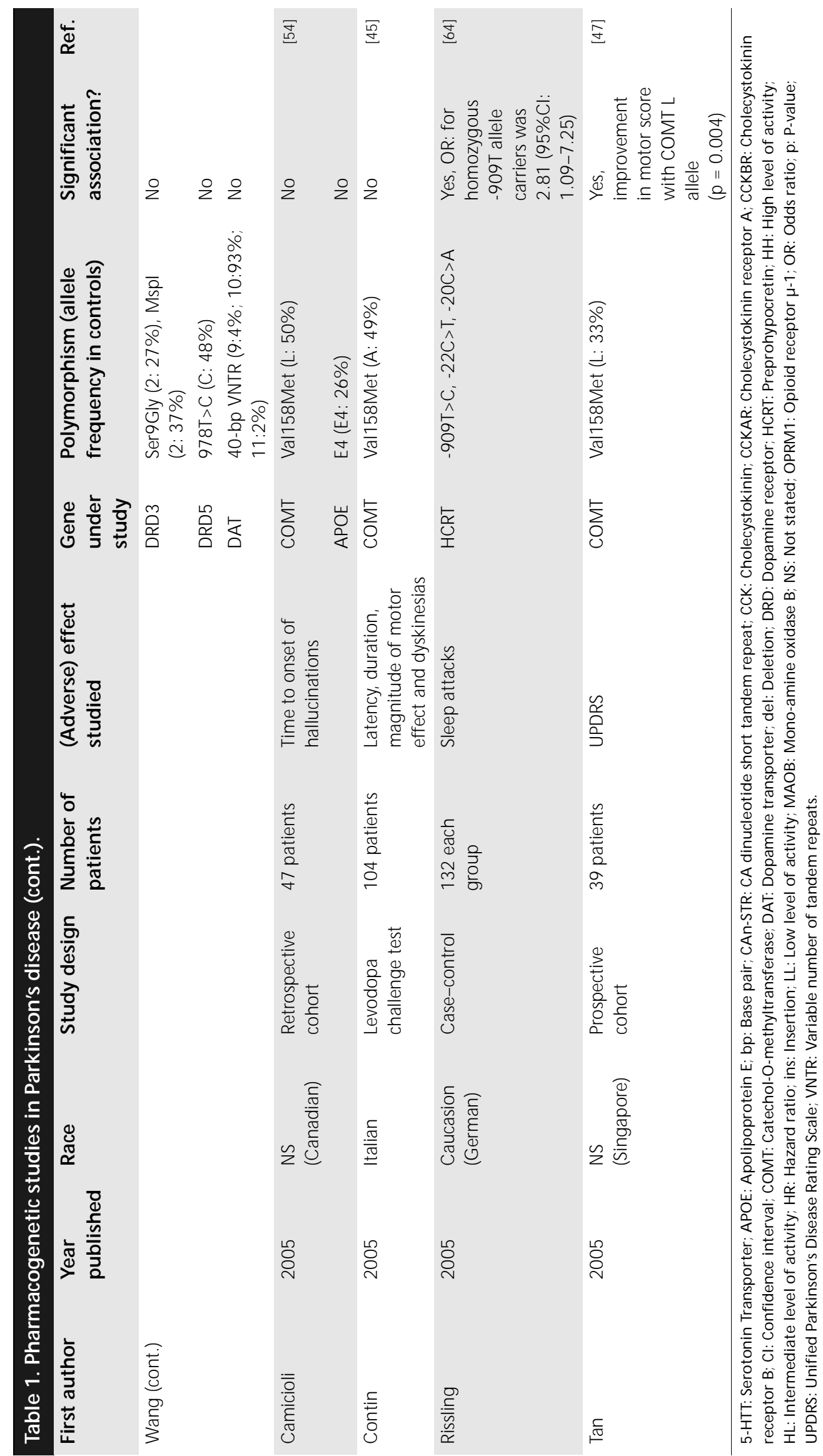




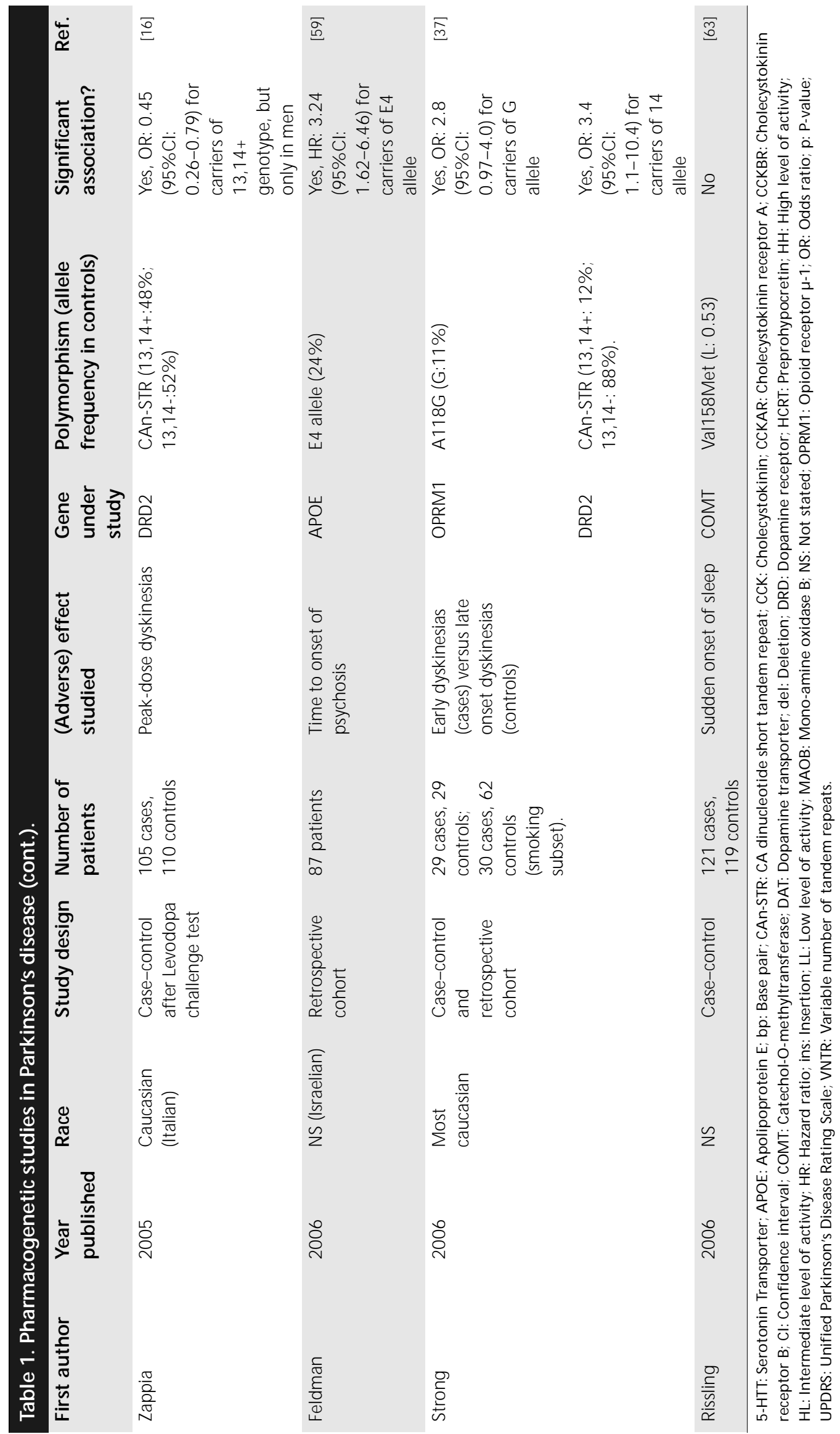


Dopamine receptor D3

TheD RD 3 gene islocated on chromosome 3 and differs from the DRD 1 and DRD 2 in representing both an autoreceptor and postsynaptic receptor [17]. The DRD 3 gene is mainly expressed in the ventral striatum and the globus pallidus [10]. Most frequently studied is the SergGly polymorphism (also known as M scl or Ball [18]). The Ser9G ly mutation of the DRD 3 gene affects the $\mathrm{N}$-terminal extracellular part of DRD3, which could disturb membrane insertion. Lately, it was demonstrated that with the Gly-9 variant, the dopamine-mediated cyclic (c)AM P response was increased, and the mitogen-associated protein kinase (M APK) signal was prolonged, as compared with the Ser-9 variant [19].

Also studied is a polymorphism in intron 5, which alters the restriction site for $\mathrm{M}$ spl [20].

The gene coding for DRD 3 is considered to be a direct gene for levodopa therapy and dopamine agonists.

\section{Dopamine receptor $\mathrm{D} 4$}

Several polymorphic sites have been described in the DRD4 gene, which is located on chromosome 11. The DRD 4 gene is widely expressed in the CN S, particularly the frontal cortex, hippocampus, amygdala and hypothalamus, and is polymorphic with respect to a 48 base pair (bp) sequence occurring in 2- to 11-fold repeat in the third exon of DRD $4[21,22]$. This segment codes for a 16 amino acid repeated sequence in the third intracellular loop of DRD 4 probably involved in G-protein binding. In cultured cells the sevenfold repeat has a blunted response to dopamine inhibition of CAM P formation [23]. It is shown that the long form has different binding properties with spiperone analogues as contrasted with the shorter forms [22].

The gene coding for DRD 4 is considered to be a direct gene for levodopa therapy and some dopamine agonists.

\section{Dopamine receptor D5}

The DRD 5 gene, located on chromosome 4, is mainly expressed in the lateral mammillary nuclei, in the anterior pretectal nuclei an in several layers of the hippocampus [24]. Due to the similarity in structure and function to $D R D 1$, it may also be involved in the pharmacological treatment of PD. Polymorphisms in this gene could be implicated in the susceptibility to complications of long-term levodopa use [25]. The gene coding for DRD 5 is considered to be a direct gene for levodopa therapy.
Dopamine transporter

The dopamine transporter (DAT) gene (SLC6A3) is located on chromosome 5. DAT takes released dopamine back up into presynaptic terminals. Interindividual genetic differences in DAT that controls the presynaptic uptake of dopamine in the dopaminergic neurons of the nigrostriatal system may also play a role in the therapeutic outcome of PD [26]. A 40-bp variable number of tandem repeats (VNTR) in the 3' UTR is identified and possibly affects gene expression [26]. The gene coding for DAT is considered to be a direct gene for levodopa therapy.

Catechol-O-methyltransferase

The gene coding for COMT is located on chromosome 22. The COMT protein occurs as two distinct forms: a soluble form found in cell cytoplasm (S-COM T) and a longer, membranebound form (M B-COMT). The MB-COMT is the more prevalent form in the brain [27]. COM T metabolizes and inactivates compounds including dopamine and levodopa. The level of COMT activity is polymorphic with a trimodal distribution of low (LL), intermediate $(H L)$ and high levels of activity $(\mathrm{H} \mathrm{H})$. The high activity is coded for by a valine residue and the low activity by a methionine protein located at protein position 158 for the MB-COMT form and located at protein position 108 for the S-COMT form [28,29]. A decreased COMT activity may result in prolonged dopamine levels. The gene coding for COM T is considered to be a direct gene for levodopa therapy and COM T inhibitor therapy.

\section{Monoamine oxidase $B$}

M onoamine oxidase ( $M A O$ ) is a mitochondrial enzyme involved in the degradation of biogenic amines, such as dopamine. MAO is classified as A or B on the basis of differential substrate specificities and differential sensitivity to inhibitors. $\mathrm{MAOA}$ and $\mathrm{MAOB}$ are encoded by $X$ chromosome-linked genes [30]. $A$ genetic polymorphism in $M A O B$ is known in intron 13 (Tsp45I) that is associated with different levels of MAOB enzyme activity in the human brain. It is postulated that there may be a cis-regulatory element in linkage disequilibrium with the intron 13 single nucleotide polymorphism (SNP) that alters MAOB enzyme activity [31]. The gene coding for $M A O B$ is considered to be a direct gene for levodopa therapy and $\mathrm{MAOB}$ inhibitors. 
Cholecystokinin gene, cholecystokinin A receptor \& cholecystokinin B receptor CCK, a neuropeptide found in the gut and CN S, has been implicated in dopaminergic regulation. The gene coding for CCK is located on chromosome 3. CCK receptors are divided into two types: cholecystokinin A receptor (CCKAR), located on chromosome 4, and cholecystokinin B receptor (CCKBR), located on chromosome 11. CCKAR mediates the action of CCK on contraction of the gallbladder, secretion of pancreatic amylase and gastric emptying. CCKBR activity is associated with increased neuronal firing, anxiety and nociception. In addition, CCK modulates the release of dopamine and dopamine-related behaviors in the mesolimbic pathway, where CCK and dopamine coexist [32]. The genes coding for CCK, CCKAR and CCKBR are considered to be an indirect gene for dopaminergic therapy.

\section{Apolipoprotein E}

APO E, with its gene located on chromosome 19, binds the amyloid- $\beta$ peptide. The major isoforms of human APOE are coded for by three alleles (E2, E3 and E4). The E2, E3 and E4 isoforms differ in amino acid sequence at two sites, residue 112 (called site $A$ ) and residue 158 (called site $B$ ). At sites A/B, APOE2, -E3 and -E4 contain cysteine/cysteine, cysteine/arginine and arginine/arginine, respectively [33,34]. An increased frequency of the $\mathrm{E} 4$ allele has been associated with a higher frequency of Alzheimer's disease [35]. The gene coding for APO E is considered to be an indirect gene for dopaminergic therapy.

\section{$\mu 1$ opioid receptor}

The $\mu 1$ opioid receptor (OPRM 1) gene is located on chromosome 6 . The most common genetic variant is the $\mathrm{A} 118 \mathrm{G}$ polymorphism, coding for an AsnN 40Asp change, which is carried by $20 \%$ of Caucasians. This polymorphism has been shown to increase binding affinity and functional potency of the endogenous opioid peptide $\beta$-endorphin [36]. It is hypothesized that OPRM 1 could have a role in developing dyskinesias, as opioids are cotransmitters in both the direct and the indirect basal ganglia pathways [37]. The gene coding for OPRM 1 is considered to be an indirect gene for dopaminergic therapy.

\section{Serotonin transporter}

Serotonin $(5-\mathrm{H} T)$ is a neurotransmitter in the central and peripheral nervous systems, with its coding gene located on chromosome 17. Following release, 5-HT is actively cleared from synaptic spaces by $5-\mathrm{HT}$ transporter $(\mathrm{T})$. A few polymorphisms in 5-H TT have been detected. Experiments have demonstrated a long and a short variant of the 5-H TT gene, with the long variant leading to higher 5-H TT mRN A concentrations. This polymorphism consists of a 44-bp insertion or deletion involving repeat elements 6-8 and is referred to as 5-H T TLPR [38,39]. The gene coding for 5-H TT is considered to be an indirect gene for dopaminergic therapy.

\section{Preprohypocretin}

The human preprohypocretin gene (H CRT; pre proorexin) is located on chromosome 17 and encodes a hypothalamic neuropeptide precursor protein that could play a role in the pathophysiology of narcolepsy [40]. HCRT gene polymorphisms are located on position -909T, $-22 \mathrm{C}>\mathrm{T}$ and $-20 \mathrm{C}>\mathrm{A}$ in the $5^{\prime} \mathrm{UTR}$, which have been studied in relation to the occurrence of sleep attacks in patients with PD [40-42]. The gene coding for HCRT is considered to be an indirect gene for dopaminergic therapy.

\section{Polymorphisms associated with}

drug efficacy

Levodopa

All studies investigating the influence of polymorphisms on levodopa efficacy studied a relation with a mono-amine transporter system polymorphism (DAT) or a mono-amine degradation enzyme polymorphism (COMT and MAOB). Response to a single oral dose of levodopa, measured as response latency, duration and magnitude of the response and dyskinesias, did not differ between ninefold copy carriers and tenfold copy homozygotes of the 40-bp VNTR polymorphism in the D AT gene [43]. Similarly, no differences in levodopa response were found between groups with different COMT Val158M et gene polymorphism $[44,45]$. Bialecka and colleagues did not observesignificant differences in CO M T genotype and $\mathrm{MAOB}$ genotype between patients needing less than $500 \mathrm{mg}$ levodopa/day and those needing more than $500 \mathrm{mg}$ levodopa/day during the first 5 years of disease [46]. Separate evaluation of males and females, because of location of the MAOB gene on chromosome $X$, did not alter the results significantly. Tan and colleagues observed that low-activity COMT homozygotes had a better improvement on the motor score with high-dose pyridoxine adjunct therapy [47]. It is suggested that high-dose pyridoxine, which is a cofactor for D O PA decarboxylase, facilitates the conversion of levodopa to dopamine in the brain. 
Catechol-O-methyltransferase inhibitor The relation between the clinical efficacy of the COMT inhibitor tolcapone and the COMT Val158M et gene polymorphism in patients with PD was studied by Chong and colleagues [48]. Patients were divided into those who had a stable response to levodopa and those who were considered to be fluctuators. Furthermore, nine patients who had severe diarrhea as a side effect were enrolled to determine the possible relationship with COMT genotype. No significant association between genotype and improvement in Unified Parkinson's Disease Rating Scale (UPDRS) score at 1-2 weeks treatment until 6 months of treatment was found after adjustment for the severity of PD, the tolcapone dose and initial differences in baseline scores. No significant relation was seen in change in daily levodopa intake and COM T genotype. Furthermore, no relation was found between COM T genotype and diarrhea.

Wearing off \& 'on-off' phenomena Wearing-off effects are defined as reemergence of parkinsonian symptoms prior to intake of the next levodopa dose. 'On-off' phenomena are denoted as sudden, unpredictable fluctuations of motor symptoms. In the studies of Kaiser and colleagues [26] and Wang and colleagues [12,25], these two symptoms were recorded as one item, and are denoted as motor fluctuations by Wang and colleagues. Patients who experienced on-off/wearing off and those who did not, showed no difference in frequencies of polymorphisms in the DRD2 gene (TaqlA, TaqlB, TaqID, Pro310Ser, Ser311Cys, Val96Ala, $-241 A>G$ and $-141 C$ ins/del), the DRD 3 gene (SergGly and the M spl), the DRD 4 gene (48-bp VNTR, 12-bp repeat and the 13-bp deletion variant) and DAT gene (40-bp VNTR) [26]. Wang and colleagues investigated whether polymorphisms in the DRD 2 gene (TaqlA), DRD 3 gene (Ser9Gly and M spl polymorphisms) and DRD 5 gene $(978 T>C$ ) were associated with a higher risk of developing motor fluctuations in patients with PD using levodopa [12,25]. Patients with motor fluctuations and those without motor fluctuations were individually matched. The frequency of the DRD 2 TaqlA non-A2 carriers in patients with motor fluctuations was higher $(33 \%)$ than in those without motor fluctuations $(10 \%)$. The odds ratio (OR) for developing motor fluctuations for non-A2 carriers versus A2 carriers was $4.33 \quad(95 \%$ confidence interval
[CI]: 1.27-14.78). The DRD 3 and D RD 5 genotypic frequencies did not differ between patients with or without motor fluctuations.

\section{Polymorphisms associated with drug tolerance \\ Dyskinesias}

Peak-dose dyskinesias are common, disabling side effects of levodopa treatment and occur in approximately $30-80 \%$ of the patients with PD . Female gender, earlier age at onset of PD and a longer duration of levodopa therapy have been associated with a higher risk of developing peakdose dyskinesias [49]. G enetic factors could also contribute to individual variability in the development of peak-dose dyskinesias.

Oliveri and colleagues [49], Zappia and colleagues [16] and Strong and colleagues [37] investigated whether the DRD2 CAn-STR gene polymorphism is associated with the risk of levodopa induced peak-dose dyskinesias in PD. Due to the low frequencies of some genotypes, subjects were categorized as subjects carrying at least one of the 13 copy or 14 copy allele $(13,14+)$ or as subjects carrying neither a 13 copy nor a 14 copy allele (13,14-). O liveri and colleagues found that the gender-adjusted $O R$ for developing peak-dose dyskinesias for the 13,14+ genotypes was 0.28 (95\% Cl: 0.11-0.77) [49]. This result is corroborated by Zappia and colleagues, who found an OR of 0.45 (95\% Cl: 0.26-0.79). H owever, when taking gender into account, Zappia and colleagues found out that only men carrying the 13,14+ genotype had a decreased risk for peakdose dyskinesias, whereas in women the genotype status did not influence the risk [16]. In contrast, Strong and coworkers found that the 14 allele and the 14/15 genotype was a risk-factor for dyskine sias (crude OR for 14 allele: 3.4; 95\% CI: 1.1-10.4) [37].

Furthermore, O liveri and colleagues could not demonstrate that three polymorphisms of the DRD 1 gene (-48G $>A, 1403 T>C$ and Ser421Ser) were associated with the risk of levodopa-induced peak-dose dyskinesias.

Kaiser and colleagues assessed whether polymorphisms in the DRD 2 gene (TaqlA, TaqlB, TaqID, Pro310Ser, Ser311Cys, Val96Ala, A>G 241 and $-141 \mathrm{C}$ ins/del polymorphisms), the DRD 3 gene (Ser9Gly and the M spl polymorphism), the DRD 4 gene (48-bp VNTR, 12-bp repeat and the 13-bp deletion variant) and the DAT gene (the 40-bp VNTR) are associated with dyskinesias in patients with PD on levodopa [26]. Patients with dyskinesias on 
levodopa were more frequent carriers of the ninefold copy 40-bp D AT allele than all other patients (53.2 vs $34.8 \%$ ). The OR for developing dyskinesias in patients with PD on levodopa carrying the ninefold copy 40-bp DAT allele was 2.5 (95\% Cl: 1.3-4.7). No significant genotype differences could be found between patients with or without dyskinesias for all other genes studied.

Strong and colleagues found a borderline significant association between OPRM 1 G-allele frequency and the risk of early dyskinesias versus late dyskinesias for PD patients on levodopa (crude O R: 2.8; 95\% Cl: 0.97-4.0) [37].

Hallucinations

$\mathrm{H}$ allucinations, mainly of a visual nature, affect approximately $25 \%$ of patients with PD. Independent risk factors for visual hallucinations are cognitive decline, daytime somnolence and a long duration of PD. Hallucinations are common side effects of dopaminergic treatment in $P D$, but dopaminergic treatment alone is not sufficient to explain the occurrence of all visual hallucinations [50]. A total of 12 studies have been performed investigating the relation between genetic variability and the occurrence of hallucinations on dopaminergic treatment. Goetz and colleagues determined the relation between DRD 1, DRD2, DRD 3, DRD 4 and APOE gene polymorphisms and hallucinations in patients with PD [51]. Included were patients with hallucinations and patients without hallucinations matched for age and dopaminergic medication. The frequency of the $D R D 1$ genotype (-48G $>A$ ) was not different between the patients with and without hallucinations. There were too few DRD 2 311Cys alleles to compare DRD 2 allele genotypes or frequencies. There was no statistical difference in the distribution of the DRD 3 Ser9G ly genotype between the cases and controls. There was, however, a borderline significant difference in D RD 3 allelefrequency ( $p=0.047)$. No statistical differences in the distribution of the DRD 4 48-bp genotype (two- to eight-fold copy alleles) between cases and controls were determined, comparing those with any long allele (sixto eight-fold copy) with those with only short alleles. There was neither a significant difference between cases and controls for the APOE genotype distribution or the APO E4 allele frequency.

Kaiser and colleagues observed that patients with psychotic episodes on levodopa were more frequent carriers of the DAT ninefold 40-bp allele than all other patients $(60.0$ vs $36.8 \%$ ) [26]. The $O R$ for developing psychosis on levodopa in patients with PD carrying the ninefold copy 40-bp allele was 2.6 (95\% CI: 1.3-5.3). No significant relationship with the occurrence of psychosis could be established for polymorphisms in the DRD 2 gene (TaqlA, TaqlB, TaqlD, Pro310Ser, Ser311Cys, Val96Ala and the $A>G 241$ and -141C ins/del polymorphisms), DRD 3 gene (Ser9Gly and the M spl polymorphism) and the DRD 4 gene (48-bp VNTR, 12-bp repeat and the 13-bp deletion variant).

Wang and colleagues could not show significant differences in genotype frequencies in the DRD 2 gene (TaqIA), DRD 3 gene (Ser9G ly and M sp1), DRD 5 gene $(978 T>C)$ and DAT gene (40-bp VNTR) between PD patients on levodopa with and without hallucinations, individually matched for disease duration, age at disease onset, duration of dopaminergic therapy and gender [52].

$M$ akoff and colleagues investigated the association of polymorphisms in the DRD 2 gene (-141C ins/del and the Taql A) and DRD 3 gene (Ser9Gly) and hallucinations in patients with idiopathic PD [53]. Patients with and without hallucinations were matched for disease duration, age at disease onset, duration of dopaminergic therapy and gender. Corroborating the findings of Kaiser and Wang, the hallucinators did not differ from the nonhallucinators in the genotype frequencies of the polymorphisms in DRD 2 and DRD 3, but in a subgroup analysis of late hallucinators compared with patients with a disease duration greater than 8 years who had never experienced hallucinations during treatment, the DRD2 -141C/C genotype was more frequent in the hallucinators (OR: 3.15; $95 \% \mathrm{Cl}: 1.10-9.15)$.

$\mathrm{No}$ association was found between the CO M T Val158M et gene polymorphism and hallucinations in autopsy-proven PD, but the etiology of the hallucinations was not recorded (e.g., relationship to medications) [54].

Interesting, albeit conflicting, results have been reported on the association between hallucinations in PD and polymorphisms in the CCK gene. Wang and colleagues found that the CCK $-45 C>T$ polymorphism was more frequent in PD patients with hallucinations than in those without [55]. The $O R$ for hallucinations in patients with a $T$ allele was $4.4 \quad(95 \%$ $\mathrm{Cl}: 1.7-11.9)$. Also, the presence of the combined CCK CT/TT genotypes and CCKAR TT/TC genotypes increased the risk of visual hallucinations in PD (OR: 5.9; 95\% $\mathrm{Cl}$ : 1.7-21.6). Fuji and colleagues corroborated 
the relation between a CCK $-45 \mathrm{C}>\mathrm{T}$ polymorphism and hallucinations in PD [56], although no such relation was found by Goldman and colleagues [57]. O ther polymorphisms in the CCK gene $(196 \mathrm{G}>\mathrm{A}, 1270 \mathrm{C}>\mathrm{G}$ and $6662 C>T)$ [56], the CCKAR gene $(779 T>C)$ or the CCKBR gene $(1550 \mathrm{G}>\mathrm{A})$ were not associated with hallucinations [55,57].

Four studies have investigated the relationship between the APOE4 allele and increased risk of drug-induced hallucinations in PD. De la Fuente-Fernández and colleagues included nondemented patients with PD on chronic levodopa treatment. They demonstrated a significant association between the presence of the APOE 4 allele and hallucinations. The $\mathrm{OR}$ for hallucinations in patients with the APOE 4 allele adjusted for age, severity of parkinsonism, duration of treatment and dose of levodopa was $8.57 \quad(95 \%$ $\mathrm{Cl}: 2.25-32.59)$ [58]. This finding was supported by the study of Feldman and colleagues who found that the hazard ratio for the development of psychosis if a patient carried the APOE4 allele was 3.24 (95\% CI: 1.62-6.46) [59]. In contrast, Inzelberg and colleagues and Camicioli and colleagues could not show an association of the APOE genotype on the development of hallucinations in patients with PD $[4,54]$.

Excessive daytime sleepiness

Sleep disorders and daytime sleepiness are fre quent in patients with PD. Sleep attacks or sudden onset of sleep (SOS) are defined as abrupt episodes of unplanned sleep during activities where they are not expected to occur. Although dopaminergic agents have been known for a long time to induce somnolence, the etiology of this side effect and particularly sleep attacks or SO S is still unknown. Five studies have been performed investigating the association between genetic variability and the occurrence of sleep attacks or day-time sleepiness on dopaminergic treatment.

Paus and colleagues studied the association between polymorphisms in the DRD2 gene (141C del/ins and TaqlA), DRD 3 gene (Ser9Gly), DRD 4 gene (48-bp repeat) and 5-H TTLPR and sleep attacks in patients with PD taking dopaminergic drugs [60]. PD patients with sleep attacks and without sleep attacks were matched for dopaminergic treatment, disease duration and age. There was a highly significant association between sleep attacks without warning signs and a DRD 4 48-bp twofold copy (short) allele versus three to seven-fold copy alleles $(23.2$ vs $7.4 \% ; p<0.0001)$. There were no significant differences between cases and controls for all other polymorphisms studied. In contrast with the findings of Paus and coworkers, Rissling and colleagues found a significant difference in the DRD 2 TaqlA genotype distribution between PD patients with SOS and a control group [61]. The OR for developing SOS for homozygous carriers of allele A2 was 5.24 (95\% Cl: 1.65-16.59). N o significant difference could be demonstrated in the DRD 3 Ser9Gly gene polymorphism and the DRD 4 120-bp VNTR genotype distribution between PD patients with SOS and the control group. Frauscher and colleagues demonstrated a significant association between the COM T Val158M et polymorphism and daytime sleepiness, which was defined by a score greater than 10 on the Epworth Sleepiness Scale $(p=0.039)$ [62]. H owever, Rissling and colleagues were not able to confirm this finding in a larger study [63]. In another study, Rissling and colleagues demonstrated an association between the -909T polymorphism of the HCRT gene and SOS (OR $=2.81 ; 95 \% \mathrm{Cl}: 1.09-7.25)$ [64]. They found no association between a $-22 \mathrm{C}>T$ or $-20 \mathrm{C}>\mathrm{A}$ H CRT gene polymorphism and SO S.

\section{Discussion}

Interindividual variability in anti-PD drug response is evident both from clinical experience and drug efficacy studies and may, at least in part, be explained by genetic variability in genes coding for drug-metabolizing enzymes, drug targets or proteins involved in signaling pathways. This systematic literature review shows that relatively few efforts have been made to investigate the role of pharmacogenetics in the individual response to anti-PD drugs. H owever, some interesting, albeit nonconsistent, associations have been found.

Summarizing the main results, positive associations have been found between the occurrence of levodopa-induced dyskinesias and polymorphisms in the DRD 2 gene (CAn-STR 13 and 14 copy alleles protective $[16,49]$ and in contrary 14 copy allele as risk factor [37]), the DAT gene (ninefold copy) [26] and OPRM $1 \mathrm{G}$-allele [37]. Also, motor fluctuations have been associated with the D RD 2 TaqlA polymorphism [12], although others could not replicate this finding [26]. Conflicting results have been reported concerning the occurrence of hallucinations in PD and genetic polymorphisms. W hile some authors found significant associations between hallucinations and polymorphisms in the DAT gene [26], the CCK gene [55,56] or the APOE 
gene [58,59], others failed to replicate these results $[4,51-54,57]$. Associations were found between seep attacks without warning signs and a D RD 4 gene or a HCRT gene polymorphism [60,64]. 0 thers found a positive association with a D RD 2 gene or a COM T gene polymorphism [61,62], although the latter could not be replicated $[60,63]$.

Some remarks on the studies presented can be made, and many of these have been discussed previously in reviews of the pharmacogenetics of antipsychotic and antidepressant response [5,65-67]. Firstly, only a few replication studies have been performed, both with regard to studies with negative findings and those with positive findings. O bviously, it is important that replication studies are being performed for confirmation in order to establish the true association of the polymorphisms studied.

M oreover, the methodology of the replication studies that have been performed differ from the original studies with respect to design and factors such as case selection and race. 0 bviously, using case definitions and matching criteria of the controls different from the original study could influence the results. Also, differences in race distribution could influence the findings, as it is known that allele frequencies, as well as linkage disequilibria, may vary among races. For example, Asians and African-Americans have a lower frequency of the low activity allele of the COM T Val158M et gene polymorphism than Caucasians [68].

Furthermore, due to small sample sizes most of the pharmacogenetic studies in PD are likely to be underpowered. The sample size in the case-control studies as reviewed here was limited to 23-147 cases. A typical sample size of wellpowered pharmacogenetic case-control studies is 300 cases and 600 controls to detect a true $0 \mathrm{R}$ of 1.5 with $80 \%$ power and typel error probability $(\alpha)$ of 0.05 [69]. Moreover, the allele frequency is an important factor in the power of pharmacogenetic studies. If the variants are rare the necessary sample size steeply increases. In the reported studies some allele frequencies were below $10 \%$ in the control group (some CCK gene polymorphisms, one CCKBR gene polymorphism, one DRD 1 gene polymorphism and some D RD 2 gene polymorphisms). Thus, future pharmacogenetic studies with these alleles will probably require larger samples.

The emphasis in the studies published until now has been on SN PS and VNTR. Some of these are located in the coding or regulatory regions of genes that have an a priori relevance to the drug response or adverse effect phenotype under study. However, some of the SN Ps or VN TR are located in noncoding regions and the implications of these polymorphisms remain unclear. 0 ne explanation could be that the polymorphisms in noncoding regions are in linkage disequilibrium with other, possibly unknown, functional variants [70]. As in all association studies, a positive association between a gene polymorphism and drug response does not necessarily imply a causal relation.

PD is a complex trait, and so is its pharmacological treatment. It is therefore likely that several genes together are implicated in the response to anti-PD drugs and susceptibility to adverse effects. Therefore, future studies on pharmacogenetics of drug effects in PD require a polygenic approach. Indeed, relatively few examples (such as thiopurine drugs) of largely monogenic drug response are known [71].

A final remark is that the studies performed until now were all candidategene-driven. The findings are therefore easier to interpret, since only genes are studied in which the role of drug treatment in PD is more or less established. H owever, this approach may have limitations, as many regulatory processes in dopaminergic signaling are not known. In contrast, wholegenome screening does not have this limitation and may lead to finding novel genes of interest, but instead data-analysis and interpretation is much more complex.

\section{Future perspective}

To date, genetic associations with levodopa response, COM T inhibitor response and common drug side-effects, such as dyskinesias, hallucinations and excessive daytime sleepiness have been investigated. No pharmacogenetics studies have been performed on dopamine agonists response and side effects. In the future it may be worth looking at variability in the suggested genetic background of the slower decline of imaged D AT by pramipexole [72,73]. Investigation of the role of genetic variability in susceptibility to side-effects, such as pathological gambling, punding and hypersexuality, may also be of interest [74-77]. These side effects are probably under-reported and socially disabling. Although disputed, some state that the newer dopamine agonists, pramipexole and ropinirole, have a higher incidence of these side effects $[74,77]$. As these dopamine agonists have a higher affinity for D RD 3, polymorphisms in the DRD 3 gene could be implicated. It would therefore be interesting to study the role of DRD 3 polymorphisms in PD, especially since such 
polymorphisms have been implicated in other basal ganglia disorders as welll, such as tardive dyskinesia [78] and essential tremor [19].

Another interesting side effect is the higher incidence of fibrotic reactions in lungs and hearts valves caused by ergolide dopamine agonists. It is suggested that the $5-\mathrm{H}$ T2B receptor (HTR2B) plays a role in the development of these fibrotic reactions. The involvement of polymorphisms in the HTR2B gene, which is located on chromosome 2 may be relevant to study [79].

The role of polymorphisms in the cytochrome P450 (CYP) enzymes and transporter enzymes, such as $\mathrm{P}$-glycoprotein in the response on anti-PD drug treatment have not been investigated [80]. Pergolide is partly metabolized by CYP2D 6 [81], which is known to be highly polymorphic [82]. CYP2D 6 poor metabolizers may experience a higher degree of adverse effects on pergolide. P-glycoprotein, encoded by the multidrug resistance 1 gene, is implicated in transport of substances, such as drugs, out of the brain and in the small intestine. The ergot-alkaloid bromocriptine is found to be an inhibitor of P-glycoprotein [83]. Moreover, budipine is shown to be transported from the brain by P-glycoprotein in mice [84].

In conclusion, some studies point towards genetic variation in candidate genes being involved in interindividual drug response in the treatment of PD. H owever, replication of findings and additional research with larger patient numbers and a polygenic approach is needed to establish the role of pharmacogenetics in anti-PD drugs. To date, it seems not appropriate to investigate the mentioned polymorphisms routinely or exceptionally during the clinical management of PD.

\section{Acknowledgements}

$M$ aurits Arbouw performed the literature search and wrote the initial version. Jeroen van Vugt, Toine Egberts and H enk-Jan Guchelaar participated in writing and reviewing the paper. H enk-Jan Guchelaar approved the final version of the manuscript. The authors thank Kris M ovig, Petra Poeds and $\mathrm{Cees} \mathrm{N}$ eef for their comments on the manuscript. Jeroen van Vugt's salary is fully covered by Medisch Spectrum Twente. He has received consultancy fees from Boehringer Ingeh heim, Glaxo Smith Kline, Janssen-Cilag and N ovartis. The other authors have no conflicts of interest.

\section{Executive summary}

- Pharmacotherapy is the mainstay in the treatment of Parkinson's disease (PD) and the armamentarium of drugs available for the therapy of this disease is still expanding.

- Anti-PD drugs are effective in reducing symptoms such as hypokinesia, bradykinesia, rigidity and tremor.

- Interindividual variability in anti-PD drug response is evident both from clinical experience and pharmacological studies and may be explained by genetic variability in genes encoding drug-metabolizing enzymes, drug targets or proteins involved in signaling pathways.

- Some interesting associations between genetic variants and anti-PD drug response have been found, but these are conflicting. Positive associations have been found between the occurrence of levodopa-induced dyskinesias or motor fluctuations and polymorphisms in the dopamine receptor (DR)D2 gene, between hallucinations and polymorphisms in the dopamine tranporter gene, the cholecystokinin gene and the apolipoprotein E gene and between sleep attacks without warning signs and polymorphism in the DRD2 and DRD4 genes.

- Due to small sample sizes most of the pharmacogenetic studies in PD are likely to be underpowered.

- Our literature study reveals that relatively few efforts have been made to investigate the role of pharmacogenetics in the individual response to anti-PD drugs and only few replication studies have been performed.

- Replication of findings and additional research with larger patient numbers and a polygenic approach is needed to establish the role of pharmacogenetics for anti-PD drugs.

\section{Bibliography}

Papers of special note have been highlighted as either of interest $(\bullet)$ or of considerableinterest $(\cdot \bullet)$ to readers.

1. Skipper L, Liu JJ, Tan EK: Polymorphisms in candidate genes: implications for the current treatment of Parkinson's disease. Expert. O pin. Pharmacother. 7(7), 849-855 (2006).

2. Watanabe $\mathrm{M}, \mathrm{H}$ arada $\mathrm{S}, \mathrm{N}$ akamura T et al.: Association between catechol-0 -

methyltransferase gene polymorphisms and wearing-off and dyskinesia in Parkinson's disease. N europsychobiology 48(4), 190-193 (2003).

3. Lee MS, Kim HS, Cho EK, Lim JH, Rinne JO : COM T genotype and effectiveness of entacapone in patients with fluctuating Parkinson's disease. N eurology 58(4), 564-567 (2002).

4. Inzelberg R, Paleacu D, C hapman J, Korczyn $A D$ : Re: The apolipoprotein E epsilon4 allele increases the risk of drug-induced hallucinations in Parkinson's disease. Clin. N europharmacol. 23(4), 230-231 (2000).
5. M asellis $M$, Basile VS, O zdemir V, M eltzer HY, M acciardi FM , Kennedy JL: Pharmacogenetics of antipsychotic treatment: lessons learned from clozapine. Biol. Psychiatry 47(3), 252-266 (2000).

- Review with recommendations for future pharmacogenetic studies of clozapine response are done which also apply for pharmacogenetic studies in Parkinson's disease. 
6. D earry A, Gingrich JA, Falardeau $P$, Fremeau RT Jr, Bates M D, C aron M G : $M$ olecular cloning and expression of the gene for a human $D 1$ dopamine receptor. N ature 347(6288), 72-76 (1990).

7. LeeSP, So CH, Rashid AJ et al.: D opamine $D 1$ and $D 2$ receptor $C$ o-activation generates a novel phospholipase $\mathrm{C}$-mediated calcium signal. J. Biol. Chem. 279(34),

35671-35678 (2004).

8. Cichon S, N othen M M , Erdmann J, Propping $P$ : D etection of four polymorphic sites in the human dopamine $D 1$ receptor gene (D RD 1). H um. M ol. Genet. 3(1), 209 (1994).

9. Joyce JN, M eador-Woodruff JH : Linking the family of $D 2$ receptors to neuronal circuits in human brain: insights into schizophrenia. N europsychopharmacology 16(6), 375-384 (1997).

10. Seeman $P$, W ilson $A, G$ meiner $P, K$ apur $S$ : D opamine $D 2$ and $D 3$ receptors in human putamen, caudate nucleus, and globus pallidus. Synapse 60(3), 205-211 (2006).

11. Usiello A, Baik JH, Rouge-Pont $F$ et al.: $D$ istinct functions of the two isoforms of dopamine D 2 receptors. N ature 408(6809), 199-203 (2000).

12. Wang J, Liu ZL, Chen B: Association study of dopamine D 2, D 3 receptor gene polymorphisms with motor fluctuations in PD. N eurology 56(12), 1757-1759 (2001).

13. N eville M J, Johnstone EC, Walton RT: Identification and characterization of AN KK 1: a novel kinase gene closely linked to D RD 2 on chromosome band 11q23.1. H um. M utat. 23(6), 540-545 (2004).

14. Arinami T, G ao M, H amaguchi $H$, Toru $M$ : A functional polymorphism in the promoter region of the dopamine $D 2$ receptor gene is associated with schizophrenia. $\mathrm{H}$ um. M ol. Genet. 6(4), 577-582 (1997).

15. Jonsson EG, N othen M M , G runhage F et al.: Polymorphisms in the dopamine D 2 receptor gene and their relationships to striatal dopamine receptor density of healthy volunteers. M ol. Psychiatry 4(3), 290-296 (1999).

16. Zappia M, Annesi G, N icoletti G et al.: Sex differences in clinical and genetic determinants of levodopa peak-dose dyskinesias in Parkinson disease: an exploratory study. Arch. N eurol. 62(4), 601-605 (2005).

17. Sokoloff $P, G$ iros $B, M$ artres $M P$, Bouthenet M L, Schwartz JC: M olecular cloning and characterization of a novel dopamine receptor (D 3) as a target for neuroleptics. N ature 347(6289), 146-151 (1990).
18. Muglia $P$, Jain $U, K$ ennedy JL: A transmission disequilibrium test of the Ser9/G ly dopamine D 3 receptor gene polymorphism in adult attention-deficit hyperactivity disorder. Behav. Brain Res. 130(1-2), 91-95 (2002).

19. Jeanneteau F, Funalot B, Jankovic J et al.: A functional variant of the dopamine D 3 receptor is associated with risk and age-atonset of essential tremor. Proc. N atl Acad. Sci. U SA 103(28), 10753-10758 (2006).

20. Griffon N, Crocq M A, Pilon C et al.: $D$ opamine $D 3$ receptor gene: organization, transcript variants, and polymorphism associated with schizophrenia. Am. J. M ed. Genet. 67(1), 63-70 (1996).

21. Schoots $\mathrm{O}$, Van Tol H H : The human dopamine $D 4$ receptor repeat sequences modulate expression. Pharmacogenomics] . 3(6), 343-348 (2003).

22. Van Tol H H, Wu CM, Guan H C et al.: M ultiple dopamine $D 4$ receptor variants in the human population. N ature 358(6382), 149-152 (1992).

23. Asghari V, Sanyal $S$, Buchwaldt $S$, Paterson A, Jovanovic V, Van Tol H H : M odulation of intracellular cyclic AM P levels by different human dopamine $\mathrm{D} 4$ receptor variants. J. N eurochem. 65(3), 1157-1165 (1995).

24. Tiberi $M$, JarvieKR, Silvia C et al.: Cloning, molecular characterization, and chromosomal assignment of a gene encoding a second D 1 dopamine receptor subtype: differential expression pattern in rat brain compared with the $D 1 A$ receptor. Proc. N atl Acad. Sci. U SA 88(17), 7491-7495 (1991).

25. Wang J, Liu ZL, Chen B: D opamine D 5 receptor gene polymorphism and the risk of levodopa-induced motor fluctuations in patients with Parkinson's disease. N eurosci. Lett. 308(1), 21-24 (2001).

26. Kaiser $\mathrm{R}, \mathrm{H}$ ofer $\mathrm{A}$, Grapengiesser $\mathrm{A}$ et al.: L-dopa-induced adverse effects in PD and dopamine transporter gene polymorphism. N eurology 60(11), 1750-1755 (2003).

27. Bray N J, Buckland PR, W illiams N M et al.: A haplotype implicated in schizophrenia susceptibility is associated with reduced COM T expression in human brain. Am. J. H um. Genet. 73(1), 152-161 (2003).

28. Lotta T, Vidgren J, Tilgmann C et al.: Kinetics of human soluble and membranebound catechol-0 -methyltransferase: a revised mechanism and description of the thermolabile variant of the enzyme. Biochemistry 34(13), 4202-4210 (1995).
29. Lachman H M , Papolos D F, Saito T, Yu YM , Szumlanski CL, Weinshilboum RM : $\mathrm{H}$ uman catechol-0 -methyltransferase pharmacogenetics: description of a functional polymorphism and its potential application to neuropsychiatric disorders. Pharmacogenetics 6(3), 243-250 (1996).

30. Kochersperger LM, Parker EL, Siciliano M, D arlington GJ, D enney RM : Assignment of genesfor human monoamine oxidases $A$ and $B$ to the $X$ chromosome. J. N eurosci. Res 16(4), 601-616 (1986).

31. Balciuniene J, Emilsson $L, O$ reland $L$, Pettersson $U$, Jazin E: Investigation of the functional effect of monoamine oxidase polymorphisms in human brain. Hum. Genet. 110(1), 1-7 (2002).

32. Studler JM, Javoy-Agid F, C esselin F, Legrand $J C$, Agid $Y$ : CCK-8-Immunoreactivity distribution in human brain: selective decrease in the substantia nigra from parkinsonian patients. Brain Res. 243(1), 176-179 (1982).

33. Weisgraber KH, Rall SC Jr, M ahley RW: H uman E apoprotein heterogeneity. Cysteine-arginine interchanges in the amino acid sequence of the apo-E isoforms. J. Biol. Chem. 256(17), 9077-9083 (1981).

34. Rall SC Jr, Weisgraber KH, M ahley RW: H uman apolipoprotein $\mathrm{E}$. The complete amino acid sequence. J. Biol. Chem. 257(8): 4171-4178 (1982).

35. Corder EH, Saunders AM, Strittmatter WJ et al.: $G$ ene dose of apolipoprotein $E$ type 4 allele and the risk of Alzheimer's disease in late onset families. Science 261(5123), 921-923 (1993).

36. Bond $C$, LaForge KS, Tian $M$ et al.: Single nucleotide polymorphism in the human $\mu$ opioid receptor gene alters $\beta$-endorphin binding and activity: possible implications for opiate addiction. Proc. N atl Acad. Sci. U SA 95(16), 9608-9613 (1998).

37. StrongJA, D alvi A, RevillaFJ et al.: Genotype and smoking history affect risk of levodopa-induced dyskinesias in Parkinson's disease. M ov. Disord. 21(5), 654-659 (2006).

38. H eils A, Teufel A, Petri $S$ et al.: Functional promoter and polyadenylation site mapping of the human serotonin (5-H T) transporter gene. J. N eural Transm. Gen. Sect. 102(3), 247-254 (1995).

39. Heils A, Teufel A, Petri $S$ et al.: Allelic variation of human serotonin transporter gene expression. J. N eurochem. 66(6), 2621-2624 (1996).

40. Gencik M, D ahmen N, W ieczorek S et al.: A prepro-orexin gene polymorphism is associated with narcolepsy. N eurology 56(1), 115-117 (2001). 
41. H ungs $M$, Lin L, O kun M , M ignot E: Polymorphisms in the vicinity of the hypocretin/orexin are not associated with human narcolepsy. N eurology 57(10), 1893-1895 (2001).

42. Peyron C, Faraco J, Rogers W et al.: A mutation in a case of early onset narcolepsy and a generalized absence of hypocretin peptides in human narcoleptic brains. Nat. M ed. 6(9), 991-997 (2000).

43. Contin $M, M$ artinelli $P, M$ ochi $M$ et al.: D opamine transporter gene polymorphism, spect imaging, and levodopa response in patients with Parkinson disease. Clin. N europharmacol. 27(3), 111-115 (2004).

44. Lee M S, Lyoo CH, U Imanen I, Syvanen AC, Rinne J O: G enotypes of catechol-0 -methyltransferase and response to levodopa treatment in patients with Parkinson's disease. N eurosci. Lett. 298(2), 131-134 (2001).

45. Contin M, M artinelli P, M ochi M, RivaR, Albani F, Baruzzi A: G enetic polymorphism of catechol-0 -methyltransferase and levodopa pharmacokinetic-pharmacodynamic pattern in patients with Parkinson's disease. M ov. Disord. 20(6), 734-739 (2005).

46. Bialecka M, D rozdzik M, Klodowska-Duda $G$ et al.: The effect of monoamine oxidase $B$ (M AOB) and catechol-0 -methyltransferase (COM T) polymorphisms on levodopa therapy in patients with sporadic Parkinson's disease. Acta N eurol. Scand. 110(4), 260-266 (2004).

47. Tan EK, Cheah SY, Fook-Chong S et al. Functional COM T variant predicts response to high dose pyridoxine in Parkinson's disease. Am. J. M ed. G enet. B N europsychiatr. Genet. 137(1), 1-4 (2005).

48. Chong DJ, Suchowersky O, Szumlanski C, Weinshilboum RM , Brant R, Campbell NR: The relationship between COM T genotype and the clinical effectiveness of tolcapone, a COM T inhibitor, in patientswith Parkinson's disease. Clin. N europharmacol. 23(3), 143-148 (2000).

49. Oliveri RL, Annesi G, Zappia M et al.: $D$ opamine $D 2$ receptor gene polymorphism and the risk of levodopa-induced dyskinesias in PD . N eurology 53(7), 1425-1430 (1999).

- First study to investigate pharmacogenetics of levodopa-induced motor complications.

50. Fenelon G, M ahieux F, H uon R, Ziegler M: $H$ allucinations in Parkinson's disease: prevalence, phenomenology and risk factors. Brain 123(Pt 4), 733-745 (2000).

51. Goetz CG, Burke PF, Leurgans $S$ et al.: $G$ enetic variation analysis in parkinson disease patients with and without hallucinations: case-control study. Arch. N eurol. 58(2), 209-213 (2001).

52. Wang J, Zhao C, Chen B, Liu ZL: Polymorphisms of dopamine receptor and transporter genes and hallucinations in Parkinson's disease. N eurosci. Lett. 355(3), 193-196 (2004).

53. M akoff AJ, Graham JM , Arranz MJ et al.: Association study of dopamine receptor gene polymorphisms with drug-induced hallucinations in patients with idiopathic Parkinson's disease. Pharmacogenetics 10(1), 43-48 (2000).

54. Camicioli $R$, Rajput $A$, Rajput $M$ et al.: Apolipoprotein E epsilon4 and catechol-0 -methyltransferase alleles in autopsy-proven Parkinson's disease: relationship to dementia and hallucinations. M ov. Disord. 20(8), 989-994 (2005).

55. Wang J, Si YM, Liu ZL, Yu L: Cholecystokinin, cholecystokinin-A receptor and cholecystokinin-B receptor gene polymorphisms in Parkinson's disease. Pharmacogenetics 13(6), 365-369 (2003).

56. Fujii $\mathrm{C}, \mathrm{H}$ arada $\mathrm{S}, \mathrm{O}$ hkoshi $\mathrm{N}$ et al.: Association between polymorphism of the cholecystokinin gene and idiopathic Parkinson's disease. Clin. Genet. 56(5), 394-399 (1999).

57. Goldman JG, Goetz CG, Berry-Kravis E, Leurgans S, Zhou L: G enetic polymorphismsin Parkinson disease subjects with and without hallucinations: an analysis of the cholecystokinin system. Arch. N eurol. 61(8), 1280-1284 (2004).

58. de la Fuente-Fernández $R, N$ unez $M A$, Lopez E: The apolipoprotein E epsilon 4 allele increases the risk of drug-induced hallucinations in Parkinson's disease. Clin. N europharmacol. 22(4), 226-230 (1999).

59. Feldman B, Chapman J, Korczyn AD: Apolipoprotein epsilon4 advances appearance of psychosis in patients with Parkinson's disease. Acta N eurol. Scand. 113(1), 14-17 (2006).

60. Paus $S$, Seeger $G$, Brecht $H M$ et al.: Association study of dopamine D 2, D 3, D 4 receptor and serotonin transporter gene polymorphisms with sleep attacks in Parkinson's disease. M ov. D isord. 19(6), 705-707 (2004).

61. Rissling I, Geller F, Bandmann $O$ et al.: D opamine receptor gene polymorphisms in Parkinson's disease patients reporting "sleep attacks". M ov. D isord. 19(11), 1279-1284 (2004).

62. Frauscher $B, H$ ogl $B, M$ aret $S$ et al.: Association of daytime sleepiness with COM T polymorphism in patients with parkinson disease: a pilot study. Slęp 27(4), 733-736 (2004).
63. Rissling I, Frauscher B, Kronenberg $\mathrm{F}$ et al.: $D$ aytime sleepiness and the COM T val158met polymorphism in patients with Parkinson disease. Sleep 29(1), 108-111 (2006).

64. Rissling I, Korner $Y$, G eller $F$, Stiasny-Kolster K, O ertel WH, M oller JC: Preprohypocretin polymorphisms in Parkinson disease patients reporting "sleep attacks". Sleep 28(7), 871-875 (2005).

65. M alhotra AK, M urphy GM Jr, Kennedy JL: Pharmacogenetics of psychotropic drug response. Am. J. Psychiatry 161(5), 780-796 (2004).

66. Kirchheiner J, Nickchen $\mathrm{K}$, Bauer $\mathrm{M}$ et al.: Pharmacogenetics of antidepressants and antipsychotics: the contribution of allelic variations to the phenotype of drug response. M ol. Psychiatry 9(5), 442-473 (2004).

- Important review that intended to integrate pharmacogenetic results from clinical studies on drug response and pharmacokinetic variability into dose adjustments and therapeutic strategies.

67. Arranz M J, M unro J, O sborne S, Collier D, Kerwin RW: Applications of pharmacogenetics in psychiatry: personalisation of treatment. Expert. 0 pin. Pharmacother. 2(4), 537-542 (2001).

68. Kunugi $\mathrm{H}, \mathrm{N}$ anko $\mathrm{S}$, $\mathrm{U}$ eki $\mathrm{A}$ et al.: $\mathrm{H}$ igh and low activity alleles of catechol-0 methyltransferase gene: ethnic difference and possible association with Parkinson's disease. N eurosci. Lett. 221(2-3), 202-204 (1997).

69. Palmer LJ, Cookson W O : U sing single nucleotide polymorphisms as a means to understanding the pathophysiology of asthma. Respir. Res. 2(2), 102-112 (2001).

70. Cordell HJ, Clayton D G: Genetic association studies. Lancet 366(9491), 1121-1131 (2005).

-. Review in which the methods of design and analysis of genetic association studies are discussed as part of a series of seven papers on genetic epidemiology.

71. Klemetsdal B, Straume B, Wist E, Aarbakke J: Identification of factors regulating thiopurine methyltransferase activity in a N orwegian population. Eur. J. Clin. Pharmacol. 44(2), 147-152 (1993).

72. Pan T, Xie W, Jankovic J, Le W: Biological effects of pramipexole on dopaminergic neuron-associated genes: relevance to neuroprotection. N eurosci. Lett. 377(2), 106-109 (2005).

73. Parkinson Study Group: D opamine transporter brain imaging to assess the effects of pramipexole vs levodopa on Parkinson disease progression. JAM A 287(13), 1653-1661 (2002). 
- Study demonstrating that patients initially treated with pramipexole have a reduction in loss of striatal [123I] $\beta$-CIT uptake, used as a marker of dopamine neuron degeneration, compared with those initially treated with levodopa, during a 46-month period.

74. Dodd M L, Klos KJ, Bower JH, G eda YE, Josephs KA, Ahlskog JE: Pathological gambling caused by drugs used to treat Parkinson disease. Arch. N eurol. 62(9), 1377-1381 (2005).

75. Szarfman A, D oraiswamy PM, Tonning JM, Levine JG : Association between pathologic gambling and parkinsonian therapy as detected in the Food and D rug Administration Adverse Event database. Arch. N eurol. 63(2), 299-300 (2006).

76. Evans $A H$, Katzenschlager $R$, Paviour D et al.: Punding in Parkinson's disease: its relation to the dopamine dysregulation syndrome. M ov. D isord. 19(4), 397-405 (2004).

77. Klos KJ, Bower JH, Josephs KA, M atsumoto JY, Ahlskog JE: Pathological hypersexuality predominantly linked to adjuvant dopamine agonist therapy in Parkinson's disease and multiple system atrophy. Parkinsonism Relat. Disord. 11(6), 381-386 (2005).

78. Basile VS, M asellis M , Badri F et al.: Association of the M scl polymorphism of the dopamine $D 3$ receptor gene with tardive dyskinesia in schizophrenia. N europsychopharmacology 21(1), 17-27 (1999).

79. Lin Z, Walther D, Yu XY, D rgon T, U hl GR: The human serotonin receptor $2 \mathrm{~B}$ : coding region polymorphisms and association with vulnerability to illegal drug abuse. Pharmacogenetics 14(12), 805-811 (2004).

80. Wilkinson GR: D rug metabolism and variability among patients in drug response. N . Engl. J. M ed. 352(21), 2211-2221: 2005.

- Review describing the role of cytochrome P450 enzymes, which are important in oxidative drug metabolism.

81. Wynalda M A, W ienkers LC: Assessment of potential interactions between dopamine receptor agonists and various human cytochrome P450 enzymes using a simple in vitro inhibition screen. D rug M etab. D ispos. 25(10), 1211-1214 (1997).

82. D aly AK, Brockmoller J, Broly $F$ et al.: N omenclature for human CYP2D 6 alleles. Pharmacogenetics 6(3), 193-201 (1996).
83. Yasuda K, Lan LB, Sanglard D, Furuya K, Schuetz JD, Schuetz EG : Interaction of cytochrome P450 3A inhibitors with P-glycoprotein. J. Pharmacol. Exp. Ther. 303(1), 323-332 (2002).

84. Uhr M, Ebinger M, Rosenhagen M C, Grauer M T: The anti-Parkinson drug budipine is exported actively out of the brain by P-glycoprotein in mice. N eurosci. Lett. 383(1-2), 73-76 (2005).

\section{Websites}

101. N ational Centre for Biotechnology Information PubM ed database. www.ncbi.nlm.nih.gov/entrez/query.fcgi?D $B=$ pubmed

102. Embase database. www.embase.com

103. ISI Web of Science. http://wos.mimas.ac.uk/

104. Genetic Association D atabase - archive of human genetic association studies of complex diseases and disorders. http://geneticassociationdb.nih.gov

105. N ational Centre for Biotechnology Information - information about human genomic discoveries. www.cdc.genomics.hugenet/ 